\title{
Study Of Vaginal Microflora In Cases Of Preterm Prelabour Rupture Of Membrane (PPROM): A Case Control Study
}

\author{
Mahaseth $\mathrm{BK}^{1}, \mathrm{BC} \mathrm{D}^{2}$
}

\begin{abstract}
Background: Globally, Preterm delivery is a major contributory factor for early neonatal death. Till date definite causative factor for preterm labour has not been proven. However, the genital tract infection is considered to be the contributory factors for PPROM. Method: This case control study was conducted at Nepalgunj Medical College Teaching Hospital, Kohalpur. 100 cases enrolled in the study were divided into two groups; group A consisted of 50 cases with PPROM; and in group B 50 cases were included cases without PPROM who came to routine antenatal check-up in ANC (antenatal care) clinic. The high vaginal swab was taken from the upper one-third of the posterior wall of the vagina and sent for culture and sensitivity in all cases. Results: In group A (with PPROM) $74 \%$ of cases were culture positive and the commonest organism was E. coli which was isolated in 40\% (20/50). In group B (without PPROM) $28 \%$ of cases had culture positive, and again the commonest organism was E. coli isolated in $14 \%$ cases (7/50). This present study showed that E. coli was most sensitive to amoxyclav and staphylococcus epidermis was most sensitive to nitrofurantoin. Ceftriaxone was found to be most effective in mixed infections. Conclusions: The genital tract infections in PPROM group was very high (+ve) culture in $74 \%$ in comparison to the non PPROM group where genital tract swab showed growth in only $28 \%$ ( $p$-value 0.001). The lower genital tract infection has been considered as one of the potent cause of PPROM, so it is advised that a vaginal swab should be routinely obtained in the ANC clinic for culture and sensitivity. An appropriate antibiotic should be started in culture positive cases.
\end{abstract}

Keywords: Culture sensitivity, High Vaginal Swab, PPROM

\section{INTRODUCTION}

Approximately 1.1 million neonates died due to complications related to preterm delivery as estimated in $2010^{1}$. According to the World health organization (WHO), a baby born before 37 completed weeks of gestation. Spontaneous preterm delivery it's a major clinical challenge for the obstetricians. Preterm delivery reported worldwide between 5-13\%, even in developed countries, like the United States of America ${ }^{2,3}$. The worldwide incidence of preterm birth due to PPROM is $3-10 \%$ and causative factor responsible for PPROM is vaginal infection i.e. $(30-40 \%)$. The burden of prematurity and its related morbidity and mortality too high in Asia and Africa, approximately $85 \%$ of preterm birth occurs in this region (31\% in Africa and $54 \%$ in Asia) ${ }^{4}$. Millennium Development Goal

1. Dr. Binod Kumar Mahaseth

2. Dr. Durga B.C.

\section{Address for correspondence:}

Dr. Binod Kumar Mahaseth

Department of Obstetrics and Gynaecology

Nepalgunj Medical College \& Teaching Hospital

Kohalpur, Banke, Nepal

Email: mahaseth.binod@hotmail.com
(MDG) sets targets to reduce $50 \%$ of neonatal mortality by 2025. Vaginal infection is one of the risk factors which can be managed some how to prevent preterm pre labour rupture of membrane/ preterm delivery and improvement of maternal and neonatal health can be achieved. The study was carried out, to see the incidence of genital tract pathogens and to obtain the culture and sensitivity of organism so that antibiotics could be prescribed earlier in pregnancy with a view to prevent PPROM know the sensitivity of organism with antibiotics could be prescribed earlier in the prelabour rupture of membrane cases to prevent maternal and neonatal complications.

\section{MATERIAL AND METHODS}

This case control study was carried out at dept. of Gynae/Obs of Nepalgunj Medical College Teaching Hospital, Kohalpur between December 2017 to December 2018. A total of 100 cases were enrolled and were divided into two groups, group $A$ and group B. Group A consisted of 50 PPROM cases between 28 to 37 weeks period of pregnancy. The group B consisted of 50 cases attending ANC clinic of Nepalgunj Medical College Teaching Hospital, Kohalpur. They had no PPROM but were in the gestational period between 28 to $<37$ weeks period of pregnancy. All 100 cases had a vaginal swab done and sent culture and sensitivity. 
The following patients were excluded from study.

1. Immuno-compromised patient.

2. Pregnancy with diabetes.

3. Multiple pregnancies.

4. Pregnant lady under antibiotic (local/systemic).

5. Pregnant lady undergone per vaginal examination.

\section{RESULTS}

In the present study 50 cases with PPROM were allocated to group A; and another 50 cases which were normal (non PPROM and who came for routine antenatal check-up in ANC clinic) were allocated in group $B$. The vaginal swab was taken and sent for culture and sensitivity in both groups.

In group A (PPROM) culture showed Gram positive and Gram negative bacteria in 37 cases (74\%). Out of which $\mathrm{E}$. coli was the commonest, $40 \%$ (20/50) followed by staphylococcus aureus and staphylococcus epidermis ( $14 \%$ and $10 \%$ each). No growth was demonstrated in 13 cases (26\%)

In group B (non PPROM) no growth was demonstrated in 36 cases $(72 \%)$ and 14 cases $(28 \%)$ showed bacterial growth, in which E. coli was again the commonest 7cases (14\%), followed by staphylococcus aureus and staphylococcus epidermis ( $8 \%$ and $4 \%$ each). (Tab.I)

\begin{tabular}{|l|l|l|l|l|}
\hline $\begin{array}{l}\text { Bacterial growth } \\
\text { in culture } \\
\text { medium }\end{array}$ & Group(A) & Group (B) & Total & pvalue \\
\cline { 1 - 4 } E.coli & $20(40 \%)$ & $7(14 \%)$ & 27 & \\
\hline Klebsiella & $2(4 \%)$ & 0 & 2 & \multirow{2}{*}{0.001} \\
\cline { 1 - 4 } Staph.aureus & $7(14 \%)$ & $4(8 \%)$ & 11 & \\
\cline { 1 - 4 } Staph.epidermis & $5(10 \%)$ & $2(4 \%)$ & 7 & \\
\hline Pseudomonas & $2(4 \%)$ & 0 & 2 & \\
\hline Proteus & $1(2 \%)$ & $1(2 \%)$ & 2 & \\
\hline No growth & $13(26 \%)$ & $36(72 \%)$ & 49 & \\
\cline { 1 - 4 } Total & 50 & 50 & 100 & \\
\hline
\end{tabular}

Table I: Distribution of microflora in group (A) and group (B)

The sensitivity report showed that $\mathrm{E}$. coli is most sensitive to amoxyclav and staphylococcus epidermis is most sensitive to nitrofurantoin. Ceftriaxone is found to be most effective for mixed infections. (Table II)

\begin{tabular}{|l|l|l|l|l|l|l|l|l|}
\hline \multirow{2}{*}{$\begin{array}{l}\text { Growth within } \\
\text { culture media }\end{array}$} & \multicolumn{7}{|c|}{ Antibiotic sensitivity } & Total \\
\cline { 2 - 11 } & Amphicilin & Amoxyclav & Ceftriaxone & $\begin{array}{l}\text { Nitrofur } \\
\text { antoin }\end{array}$ & cephalexin & cefadroxil & $\begin{array}{l}\text { No } \\
\text { growth }\end{array}$ & \\
\hline Klebsiella & 0 & 0 & $9(75 \%)$ & 0 & $2(50 \%)$ & $1(50 \%)$ & 0 & 2 \\
\hline Staph.aureus & $6(54.5 . \%)$ & 0 & $327.3 \%)$ & 0 & 0 & $2(18.2 \%)$ & 0 & 11 \\
\hline Staph.epidermis & $1(14.3 \%)$ & 0 & $1(14.3 \%)$ & $3(42.9 \%)$ & $2(28.6 \%)$ & 0 & 0 & 7 \\
\hline Pseudomonas & 0 & 0 & 0 & 0 & $2(100 \%)$ & 0 & 0 & 2 \\
\hline Proteus & 0 & 0 & $1(50 \%)$ & 0 & 0 & $1(50 \%)$ & 0 & 2 \\
\hline Ecoli & 0 & 13 & $5(18.5 \%)$ & $7(25.9 \%)$ & 0 & $2(7.4 \%)$ & 0 & 27 \\
\hline No growth & 0 & 0 & 0 & 0 & 0 & 0 & 49 & 49 \\
\hline Total & 7 & 13 & 19 & 10 & 6 & 6 & 49 & 100 \\
\hline
\end{tabular}

Table II: Microflora found to be sensitive with Antibiotics
It may be noted that group A (PPROM) showed bacterial growth of vaginal swab in $74 \%$ of cases in comparison to group $B$ (non PPROM) where growth was not reported in $72 \%$ cases. This was a significant difference with a $p$-value 0.001 .

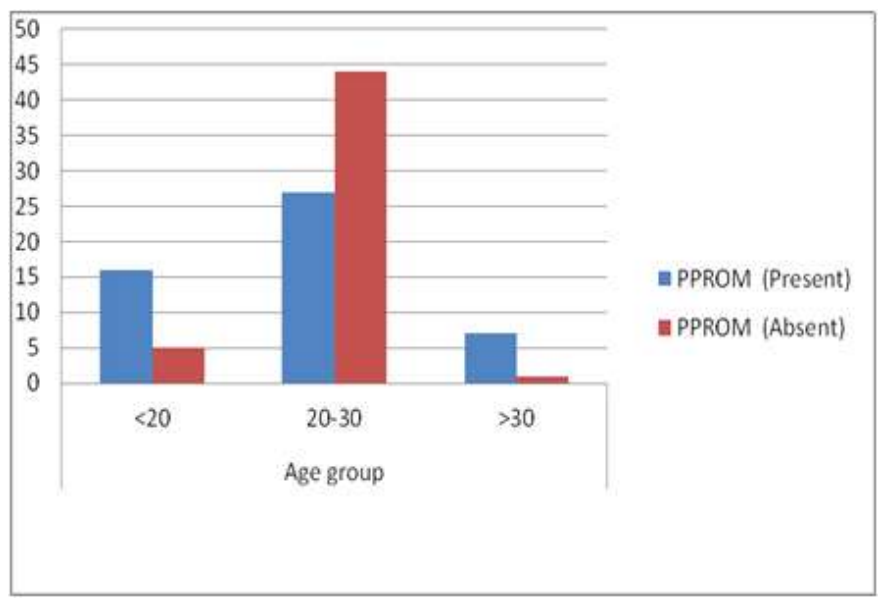

Fig 1: Distribution of cases according to the age group

In this study maximum number of participants belong to age group (20-30).fig (1)

\section{DISCUSSION}

The present study consisted of 50 cases (PPROM $+{ }^{\text {ve }}$ ) designated as group (A) and 50 cases (normal, without PPROM) were designated to group $B$

In group A $74 \%$ cases were culture positive and in group B $28 \%$ cases were culture positive,( $p$ value 0.001 ) most predominating microflora was E.coli in group A 40\% (20/50) and in group $B 14 \%(7 / 50)$, followed by staphylococcus aureus $14 \%(7 / 50)$ in group $A$ and in group $B 8 \%(4 / 50)$. Staphylococcus epidermis grew in $10 \%(5 / 50)$ in group $A$ and in group $B 4 \%$ $(2 / 50)$ respectively.

Eleje G U et $\mathrm{al}^{5}$, reported the bacterial growth in $79.05 \%$ cases in PPROM group where as in control group (non PPROM) the vagina swab grew bacteria in $6.67 \%$.

Celen s et $\mathrm{al}^{6}$ reported bacterial growth in $30.4 \%$ of cases and the incidence of E. Coli was $15.5 \%$ followed by klebsiella $4.7 \%$. The control cases (non PPROM) showed a positive bacterial culture only in $14.9 \%$ cases.

Singh S et al $\mathrm{l}^{7}$ reported the growth of bacteria in $74.6 \%$ of cases of PPROM. The predominant bacteria were E. coli $29.5 \%$ cases.

\section{CONCLUSION}

The present study showed that the rate of genital tract infections in PPROM group is very high (74\%) as in comparison to the non PPROM group were genital tract swab showed growth in only $28 \%$; p-value 0.001 . The lower genital tract infection has been considered as one of the potent cause of 
PPROM, so it is advised that a vaginal swab should be routinely obtained in the ANC clinic for culture and sensitivity. An appropriate antibiotic should be started in culture positive cases. In our study ceftriaxone was found most effective for mixed infection.

\section{REFERENCES}

1. Liu L, Johnson HL, and Cousens S. et al. Global, regional and national causes of child mortality: an updated systemic analysis for 2010 with time trends since 2000. Lancet 2012; 379:2151-61.

2. Slattery $\mathrm{MM}$ and Morrison JJ. Preterm delivery; Lancet 2002; 360: 1489-97.

3. Hamilton BE, Martin JA, and Ventura SJ.; Births: preliminary data for 2005 . Health E Stats.Hyattsville,MD,2006.http://www.cdc.gov/nchs/pro ducts/pubs/pubd/hestats/prelimbirths05/prelimbirths05 .htm. (Accessed July 15, 2007).

4. Goldenberg RL, Culhane JF, lams JD, and Romero R; epidemiology and causes of preterm birth. Lancet 2008; 371:75-84.

5. Eleje G U, Adinma J I, Ugwuanyi D C; Ikechebelu J I, Okafor $\mathrm{Cl}$, and Ezeama $\mathrm{CO}$, et al.; Genital tract microbial isolate in women with preterm pre-labour rupture of membranes in resource-constrained community setting. Journal of Obstetrics and Gynaecology 2015; 35: 465-468.

6. Çelen S, Temizkan RO, Eyi EGY, Seçkin T, Saygan S, and Özkan MS; Comparison of the Cervical Culture Results in Preterm Labor and Premature Rupture of Membranes. Erciyes Med J 2012; 34(4): 174-7

7. Singh S, Swain S, Das L, Das PC, and Sahu S; Isolation and characterizations of organisms in high vaginal swab culture in preterm pregnancy (28-37 week). Int J Reprod Contraception.2016; 5(11): 3853-3858 